\title{
Synthesis, Characterization and Antimicrobial Activities of Cobalt(II), Nickel(II) and Copper(II) Complexes of Aroylhydrazone Mixed with Aspirin
}

\author{
Olawale Folorunso Akinyele*, Temitope Oluwatola Akinnusi, Temitope Adekunle Ajayeoba, \\ Ayowole Olaolu Ayeni, Lateefah Moyosore Durosinmi \\ Department of Chemistry, Obafemi Awolowo University, Ile-Ife, Nigeria
}

Email address:

ofakinyele@oauife.edu.ng (O. F. Akinyele), ofakins@yahoo.com (O. F. Akinyele)

${ }^{*}$ Corresponding author

To cite this article:

Olawale Folorunso Akinyele, Temitope Oluwatola Akinnusi, Temitope Adekunle Ajayeoba, Ayowole Olaolu Ayeni, Lateefah Moyosore Durosinmi. Synthesis, Characterization and Antimicrobial Activities of Cobalt(II), Nickel(II) and Copper(II) Complexes of Aroylhydrazone Mixed with Aspirin. Science Journal of Chemistry. Vol. 7, No. 3, 2019, pp. 67-71. doi: 10.11648/j.sjc.20190703.13

Received: June 12, 2019; Accepted: July 23, 2019; Published: September 17, 2019

\begin{abstract}
Co}(\mathrm{II}), \mathrm{Ni}(\mathrm{II})$, and $\mathrm{Cu}(\mathrm{II})$ complexes of aroylhydrazone mixed with aspirin were synthesized and characterized by percentage metal analysis, infrared and electronic spectroscopy, melting point, solubility, molar conductance and room temperature magnetic moment measurements. Infrared spectra data revealed that the aspirin behaved as a bidentate ligand with coordination via carboxylate and carbonyl groups while the hydrazine coordinated via the azomethine nitrogen atom and carbonyl oxygen atom in the aroylhydrazone. The room temperature magnetic moment and electronic spectral data that the metal complexes possessed octahedral geometry. The molar conductance measurements of all the metal complexes in DMF indicated that they are non-electrolytes. The in vitro antimicrobial activities studies showed that the $\mathrm{Cu}(\mathrm{II})$ complex had the best activity against tested bacteria; Streptococcus spp, B. subtlis and vibro spp with inhibitory zones range of $2.0-6.0 \mathrm{~mm}$, while the Ni(II) complex showed considerable activity against gram negative bacteria; Shigella spp with inhibitory zone of $10.0 \mathrm{~mm}$ suggesting its potential as an antimicrobial agent.
\end{abstract}

Keywords: Antimicrobial, Aroylhydrazone (HL), Aspirin (HASA), Carboxylate, Azomethine

\section{Introduction}

The coordination chemistry of mixed ligands is an intensive area of study and numerous transition metal complexes of mixed ligands have been investigated [1]. Aroylhydrazones are aromatic hydrazones which belong to a class of organic compounds in the Schiff base family with the functional group $\mathrm{R}_{1}-\mathrm{CO}-\mathrm{NH}-\mathrm{N}=\mathrm{CH}-\mathrm{R}_{2}$. The hydrazone Schiff base of aroyl, acyl, and heteroaroyl compounds are known to have an additional donor site, that is $\mathrm{C}=\mathrm{O}$, which make them more versatile and flexible. This versatility has led to their emergence as good chelating agents that can form a variety of complexes with different transition metals [2].

Aspirin, or acetylsalicylic acid is a salicylate drug, and is generally used as an analgesic for minor aches and pains, to reduce fever (an antipyretic), and as an anti-inflammatory. There are works reported in literature on metal complexes of aroylhydrazone and Aspirin independently, but little is known on the mixed metal(II) complexes of aroylhydrazone with Aspirin [3-14]. Thus, in this work, we synthesized, characterized and investigated the antimicrobial activities of $\mathrm{Co}(\mathrm{II}), \mathrm{Ni}(\mathrm{II})$, and $\mathrm{Cu}(\mathrm{II})$ complexes of aroylhydrazone mixed with aspirin.

\section{Experimental}

\subsection{Materials and Methods}

Copper(II) chloride hexahydrate, cobalt(II) chloride hexahydrate, nickel(II) chloride hexahydrate, sodium ethylenediaminetetraacetic acid, 3-hydroxylbenzaldehyde and methyl-4-nitrobenzoate were of analytical grade obtained from Aldrich, May \& Baker (M\&B), BDH and LobaChemie respectively and were used as commercially obtained. The aspirin was obtained from Bond Pharmaceuticals Limited, Oyo, 
Oyo State, Nigeria. ${ }^{1} \mathrm{H}$ and ${ }^{13} \mathrm{C}$ NMR spectra were recorded in $\mathrm{d}^{6}$-DMSO on a Bruker DMX avance spectrophotometer with tetramethylsilane (TMS) as an internal standard. The IR (as $\mathrm{KBr}$ disc) spectra were recorded on Shimadzu FT-IR 8000 Spectrophotometer. The UV-Vis measurements were done on a Shimadzu UV-Vis 1800 spectrophotometer. The melting points of the ligands and the complexes were determined using Gallenkamp melting point apparatus, percentage metal was determined by complexometric titration using EDTA, and molar conductivity measurement of $1 \times 10^{-3} \mathrm{M}$ solutions in DMF at $27{ }^{\circ} \mathrm{C}$ were made using Model 4510 conductivity/TDS meter. Room temperature magnetic moment susceptibilities measurements were determined using a Sherwood susceptibility balance at $303 \mathrm{~K}$.

\subsection{Synthesis of the Co(II), Ni(II) and Cu(II) Mixed Ligand Complexes}

The reported $\mathrm{Co}(\mathrm{II}), \mathrm{Ni}(\mathrm{II})$ and $\mathrm{Cu}(\mathrm{II})$ were synthesized by adding methanolic solution of the appropriate metal salt to solution of deprotonated aspirin (using aqueous Sodium hydrogencarbonate as deprotonating agent), methanolic solution of the hydrazone ligand was then added dropwise; all in equimolar quantities. The resultant homogenous solution was stirred for 3 hours then cooled to room temperature. The precipitate formed was filtered, washed with distilled water and $60 \%$ ethanol and then dried in a desiccator over anhydrous calcium chloride.

\subsection{Antimicrobial Assay}

The antimicrobial activities of the ligands (aroylhydrazone and aspirin) and their metal(II) complexes were tested using the agar diffusion method, the surface of the agar in a Petri dish was uniformly inoculated with $0.2 \mathrm{~mL}$ of 18 hours old test microbial culture Escherichia coli, Salmonella sp, Streptococcus sp, Bacillus cereus, Bacillus subtilis, Staphylococcus $s p$, Vibro $s p$ and Shigela sp. Using a sterile cork borer, $5 \mathrm{~mm}$ wells were bored into the agar. Then $2 \mathrm{~mL}$ of $10 \mathrm{mg} / \mathrm{mL}, 7.5 \mathrm{mg} / \mathrm{mL}, 5 \mathrm{mg} / \mathrm{mL}$ and $2.5 \mathrm{mg} / \mathrm{mL}$ respectively of the concentration of each metal complex in DMSO was introduced into the wells, and the plates were allowed to stand on the bench for 1-2 hours before incubation at $37^{\circ} \mathrm{C}$ for 24 hours. Inhibitory zones (in $\mathrm{mm}$ ) were taken as a measure of antibacterial activity while experiments were conducted in duplicates and streptomycin sulphate was used as the reference drug. The sensitivity testing of compound on bacterial isolates was carried out.

\section{Results and Discussion}

\subsection{Physical Measurements}

The ligands and complexes were not soluble in water, but sparingly soluble in ethanol and methanol, their molar conductance measurements were done in DMF at $27^{\circ} \mathrm{C}$. The values obtained were in the range $2.58-35.64\left(\Omega^{-1} \mathrm{~cm}^{2} \mathrm{~mol}^{-1}\right)$, typical of covalent metal complexes [15]. The metal complexes are colored and have high melting point - stable till about $300^{\circ} \mathrm{C}$. The experimental percentage metal analysis values were very close to theoretical values, corroborating formulated masses (Table 1).

Table 1. Physical and analytical data of the ligands and metal complexes.

\begin{tabular}{|c|c|c|c|c|c|c|}
\hline Compound & Formula Mass $\left(\mathrm{gmol}^{-1}\right)$ & Colour & M. pt. $\left({ }^{\circ} \mathrm{C}\right)$ & $\%$ Metal Found (Calcd) & Yield (\%) & $\Lambda \mathrm{m}\left(\Omega^{-1} \mathrm{~cm}^{2} \mathrm{~mol}^{-1}\right)$ \\
\hline $\mathrm{L}$ & 285.15 & Pale Yellow & $266-268$ & - & 65 & - \\
\hline Aspirin (HASA) & 180.16 & White & $136-137$ & - & - & - \\
\hline$\left[\mathrm{Co}(\mathrm{ASA}) \mathrm{L}\left(\mathrm{H}_{2} \mathrm{O}\right) \mathrm{Cl}\right]$ & 577.74 & Yellow & $294-296$ & $10.43(10.61)$ & 41 & 3.00 \\
\hline$\left[\mathrm{Ni}(\mathrm{ASA}) \mathrm{L}\left(\mathrm{H}_{2} \mathrm{O}\right)_{2}\right]$ & 560.00 & Orange & $291-292$ & $14.62(14.30)$ & 70 & 3.84 \\
\hline$\left[\mathrm{Cu}(\mathrm{ASA}) \mathrm{L}\left(\mathrm{H}_{2} \mathrm{O}\right)_{2}\right]$ & 564.85 & Green & $>300$ & $11.04(11.25)$ & 57 & 3.65 \\
\hline
\end{tabular}

\subsection{Magnetic Moments and Electronic Spectra}

The observed electronic spectra data of aspirin, hydrazone and the metal complexes are presented in Table 2. In HL three bands (attributed to intraligand transitions viz of $\pi-\pi^{*}$ and $\mathrm{n}-\pi^{*}$ ) were observed at 219, 254 and $342 \mathrm{~nm}$ in the UV region and underwent considerable shifts in the metal complexes [16].

The visible spectrum of the Co(II) complex showed three $d-d$ transitions observed at 520, 760 and $820 \mathrm{~nm}$ typical of octahedral $\mathrm{Co}$ (II) complexes [7]. $\mathrm{Co}$ (II) has spectroscopic ground state term ${ }^{4} \mathrm{~F}$ and also has a ${ }^{4} \mathrm{P}$ term with the same spin and multiplicity with a $T_{1 g}$ spectroscopic state. The ${ }^{4} \mathrm{~F}$ term split into three sub energy levels namely; ${ }^{4} \mathrm{~A}_{2 \mathrm{~g}}(\mathrm{~F})$, ${ }^{4} \mathrm{~T}_{2 \mathrm{~g}}(\mathrm{~F})$ and ${ }^{4} \mathrm{~T}_{1 \mathrm{~g}}(\mathrm{~F})$, while the ${ }^{4} \mathrm{P}$ term is not split but transform into ${ }^{4} \mathrm{~T}_{1 \mathrm{~g}}(\mathrm{P})$ state. These bands are assigned to ${ }^{4} \mathrm{~T}_{1 \mathrm{~g}} \rightarrow{ }^{4} \mathrm{~T}_{2 \mathrm{~g}}(\mathrm{P}), \quad{ }^{4} \mathrm{~T}_{1 \mathrm{~g}} \rightarrow{ }^{4} \mathrm{~A}_{2 \mathrm{~g}}$ and ${ }^{4} \mathrm{~T}_{1 \mathrm{~g}} \rightarrow{ }^{4} \mathrm{~T}_{2 \mathrm{~g}}(\mathrm{~F})$ transitions respectively. The magnetic moment value of $5.21 \mathrm{BM}$ is within the range $(4.70-5.20 \mathrm{BM})$ usually observed for $\mathrm{d}^{7}$ cobalt complexes having three unpaired electrons. These values are consistent for high spin octahedral Co(II) complex and the high value may be due to the contribution of spin orbital coupling [11].

The $d-d$ bands observed at 602,650 and $800 \mathrm{~nm}$ are attributed to ${ }^{3} \mathrm{~A}_{2 \mathrm{~g}} \rightarrow{ }^{3} \mathrm{~T}_{1 \mathrm{~g}}(\mathrm{P}),{ }^{3} \mathrm{~A}_{2 \mathrm{~g}} \rightarrow{ }^{3} \mathrm{~T}_{1 \mathrm{~g}}(\mathrm{~F})$ and ${ }^{3} \mathrm{~A}_{2 \mathrm{~g}} \rightarrow{ }^{3} \mathrm{~T}_{2 \mathrm{~g}}$ transitions respectively, which are consistent with octahedral geometry for $\mathrm{Ni}(\mathrm{II})$ ion, while the bands at 452 and $550 \mathrm{~nm}$ may be due to charge transfer transitions. The magnetic moment of this complex is $2.98 \mathrm{BM}$ which agrees well with the reported values for $\mathrm{Ni}(\mathrm{II})$ complexes in octahedral environment.

In the visible region of the spectra of $\mathrm{Cu}(\mathrm{II})$ complex, (Figure 1), one band at $620 \mathrm{~nm}$ was observed and is attributed to $d-d$ transition which is consistent with the ${ }^{2} \mathrm{~T}_{2 \mathrm{~g}} \rightarrow{ }^{2} \mathrm{E}_{\mathrm{g}}$ transition in an octahedral environment. A slight shoulder at $680 \mathrm{~nm}$ is a distortion which may be due to Jahn- 
Teller effect arising from unequal occupation of the $e_{g}$ pair of orbitals which is a characteristic of $\mathrm{d}^{9}$ configuration [15]. The octahedral geometry of the $\mathrm{Cu}(\mathrm{II})$ ion in the complex is supported by the measured magnetic moment value of 2.05 BM.

Table 2. Electronic Spectral data (nm) and magnetic moments of the ligands and metal complexes.

\begin{tabular}{llll}
\hline Compounds & Intraligand transitions & CT transitions & Ligand field transitions \\
\hline $\mathrm{HL}$ & $219,254,342$ & - & - \\
$\mathrm{HASA}$ & $225,277,301$ & - & - \\
{$\left[\mathrm{Co}(\mathrm{ASA}) \mathrm{HL}\left(\mathrm{H}_{2} \mathrm{O}\right) \mathrm{Cl}\right]$} & 279,320 & - & $520,760,820$ \\
{$\left[\mathrm{Ni}(\mathrm{ASA}) \mathrm{HL}\left(\mathrm{H}_{2} \mathrm{O}\right)_{2}\right]$} & 269,355 & 452,550 & $602,650,790$ \\
{$\left[\mathrm{Cu}(\mathrm{ASA}) \mathrm{HL}\left(\mathrm{H}_{2} \mathrm{O}\right)_{2}\right]$} & $255,302,350$ & - & $620,680(\mathrm{sh})$ \\
\hline
\end{tabular}

$\mathrm{sh}=$ shoulder.

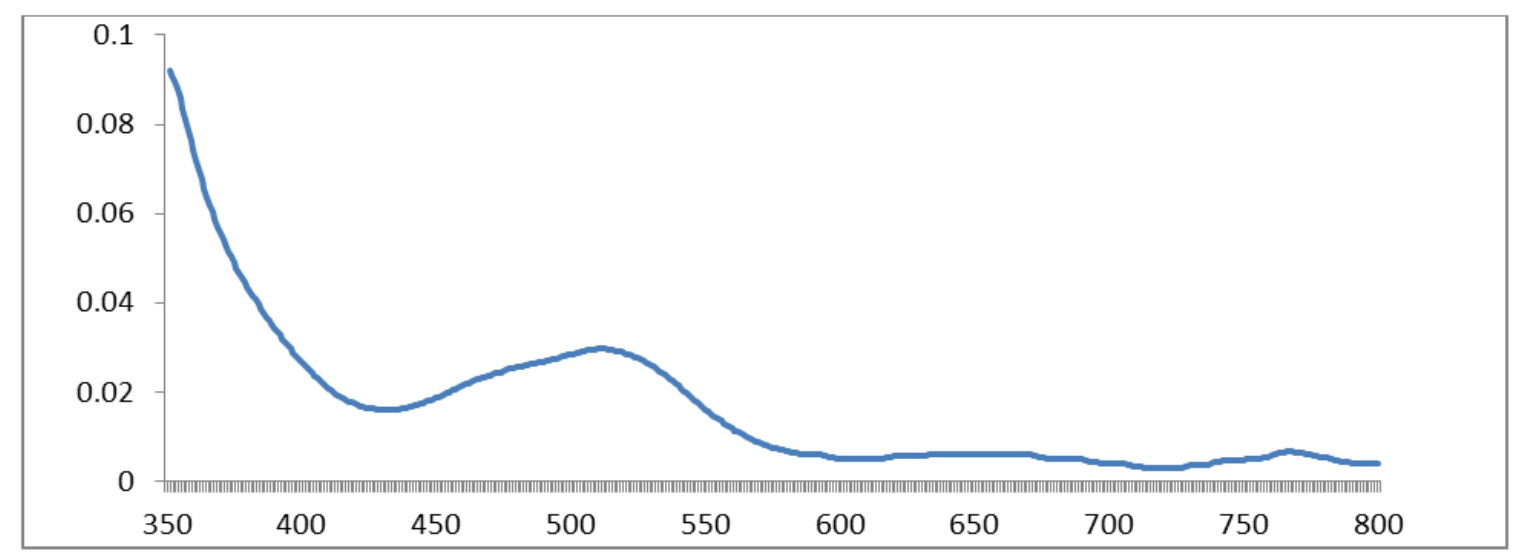

Figure 1. Visible spectrum of $\left[\mathrm{Co}(\mathrm{ASA}) \mathrm{HL}\left(\mathrm{H}_{2} \mathrm{O}\right)_{2}\right]$.

\subsection{Infrared Spectra}

The structurally significant IR bands for ligands and complexes are reported in Table 3. In the infrared spectrum of $m$-hydroxylbenzaldehyde-4-nitrobenzoylhydrazone (HL) the band at $3431 \mathrm{~cm}^{-1}$ is assigned to the phenolic $\sqrt{(\mathrm{O}-\mathrm{H})}_{\text {, }}$, band at $3284 \mathrm{~cm}^{-1}$ is assigned to $\sqrt{(N-H)}_{(\text {. The }}$. band at $1664 \mathrm{~cm}^{-1}$ is attributed to $V_{(\mathrm{C}=\mathrm{O})}$ while azomethine band $\sqrt{(\mathrm{HC}=\mathrm{N})}_{\mathrm{T}}$ in the hydrazone was observed at $1562 \mathrm{~cm}^{-1}$ as previously recorded in the literature [17]. The aspirin ligand showed characteristic band at $3489 \mathrm{~cm}^{-1} V_{(\mathrm{O}-\mathrm{H})}$ of carboxylic acid, and 1753 and $1693 \mathrm{~cm}^{-1} \sqrt{(C=O)}_{(\mathrm{C})}$ of carboxylic acid and ester respectively.

In the spectrum of Co(II) complex, there was the presence of the $\sqrt{(\mathrm{C}=\mathrm{O})}_{\text {and }}$ and the $\sqrt{(\mathrm{N}-\mathrm{H})}_{\text {s. }}$ suggests that the ligand coordinated to the metal ion in the keto form and this observation is supported by the absence of the enolic $v(\mathrm{C}-\mathrm{O})$ bands in the spectrum. The decrease in $V_{(\mathrm{C}=0)}$ band to 1645 $\mathrm{cm}^{-1}$ is an indication for the coordination of the carbonyl groups to the metal ion.

On complexation, the spectra of $\mathrm{Ni}(\mathrm{II})$ and $\mathrm{Cu}(\mathrm{II})$ complexes showed the disappearance of the $\mathcal{V}_{(\mathrm{C}=\mathrm{O})}$ and $\sqrt{(N-\mathrm{H})}_{(\mathrm{I})}$ of the hydrazone as a result of enolization/deprotonation which suggests that it coordinated to the metal ion as mononegative ligand. This is further confirmed by the enolic $\bigvee_{(\mathrm{C}-\mathrm{O})}$ bands at 1227 and $1238 \mathrm{~cm}^{-1}$ for $\mathrm{Ni}(\mathrm{II})$ and $\mathrm{Cu}$ (II) complexes respectively. The binding of the hydrazone is completed by the observation of increased $\bigvee_{(\mathrm{C}=\mathrm{N})}$ to 1585 and $1589 \mathrm{~cm}^{-1}$ in the $\mathrm{Ni}(\mathrm{II})$ and $\mathrm{Cu}(\mathrm{II})$ complexes respectively. The band at $3458 \mathrm{~cm}^{-1}$ is attributed to $V_{(\mathrm{O}-\mathrm{H})}$ of water thus indicating the presence of water in the copper complex. The shift to lower frequencies and decreased intensity of the $V_{(\mathrm{C}=0)}$ of the ester is an indication of the involvement $\bigvee_{(\mathrm{C}=\mathrm{O})}$ of the ester of the aspirin in complexation.

$V_{\left(\mathrm{COO}^{-}\right)}$ranged from $163-200 \mathrm{~cm}^{-1}$ and supports the prediction of monodentate coordination mode of the aspirin in the metal complexes [7]. In addition in the spectra of all metal complexes, $\sqrt{(M-O)}_{(1)}$ and $\sqrt{ }_{(\mathrm{M}-\mathrm{N})}$ are identified as new bands around $520-680 \mathrm{~cm}^{-1}$ while the Co(II) complex has an additional band at $462 \mathrm{~cm}^{-1}$ assigned to $V_{(\mathrm{M}-\mathrm{Cl})}$. The infrared spectrum of the copper complex is displayed in Figure 2 while the data are shown in Table 3.

Table 3. Infrared spectra data $\left(\mathrm{cm}^{-1}\right)$ of the hydrazone ligands and metal complexes mixed with aspirin.

\begin{tabular}{|c|c|c|c|c|c|c|c|c|}
\hline Compounds & $\sqrt{\text { O-H }}_{1}$ & $V_{\mathrm{N}-\mathrm{H}}$ & $\sqrt{C}=\mathbf{O}$ & $V_{\mathrm{C}=\mathrm{N}}$ & $V_{\mathrm{as} / \mathrm{sCOO}}$ & $V_{C-O}$ phenolic & $V_{\text {M-O/M-N }}$ & $V_{M-C l}$ \\
\hline $\mathrm{HL}$ & $3431 b$ & $3284 \mathrm{~m}$ & $1664 \mathrm{~s}$ & $1562 \mathrm{~s}$ & - & - & - & - \\
\hline HASA & $3489 b$ & - & $1753 \mathrm{~s}, 1693 \mathrm{~s}$ & - & - & - & - & - \\
\hline$\left[\mathrm{Co}(\mathrm{ASA}) \mathrm{L}\left(\mathrm{H}_{2} \mathrm{O}\right) \mathrm{Cl}\right]$ & $3379 \mathrm{~b}$ & $3216 \mathrm{~m}$ & $1645 \mathrm{~m}, 1632 \mathrm{~m}$ & $1593 \mathrm{~s}$ & $1512 \mathrm{~s}, 1349 \mathrm{~m}$ & - & $634 \mathrm{w}$ & $462 w$ \\
\hline$\left[\mathrm{Ni}(\mathrm{ASA}) \mathrm{L}\left(\mathrm{H}_{2} \mathrm{O}\right)_{2}\right]$ & $3379 b$ & - & - & 1585 & $1538 \mathrm{~s}, 1338 \mathrm{~m}$ & $1227 \mathrm{~m}$ & $682 \mathrm{w}, 657 \mathrm{w}$ & - \\
\hline$\left[\mathrm{Cu}(\mathrm{ASA}) \mathrm{L}\left(\mathrm{H}_{2} \mathrm{O}\right)_{2}\right]$ & $3450 \mathrm{~b}$ & - & $1614 \mathrm{~m}$ & $1589 \mathrm{~m}$ & $1525 \mathrm{~s}, 1342 \mathrm{~s}$ & $1238,1349 m$ & $601 \mathrm{w}, 524 \mathrm{w}$ & - \\
\hline
\end{tabular}




\section{ФSHIMADZU}

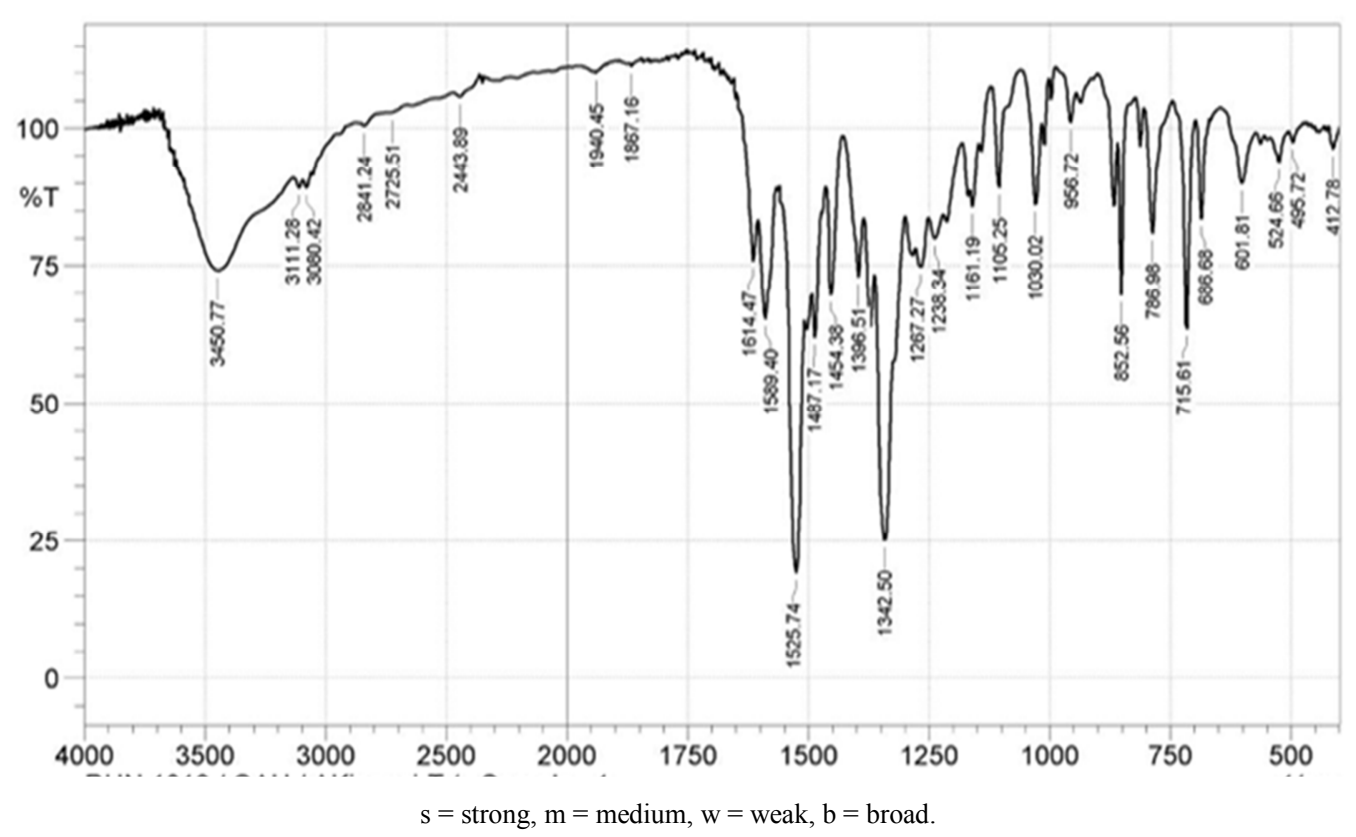

Figure 2. Infrared spectrum of the Copper complex.

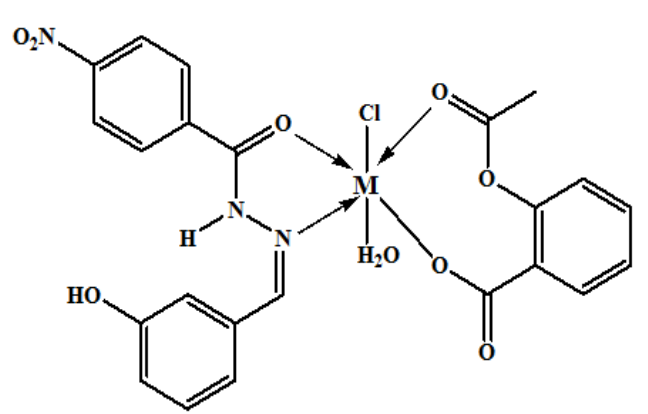

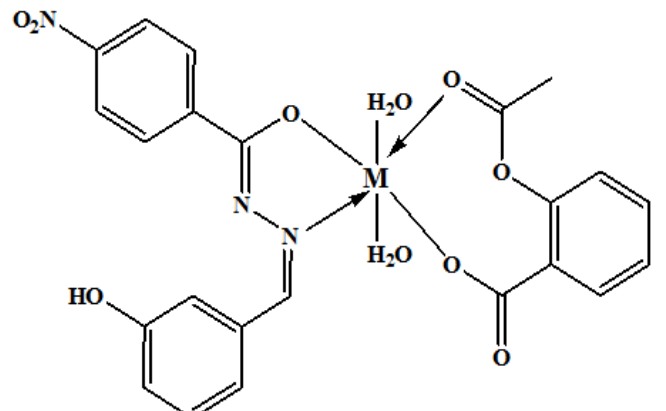

Figure 3. Proposed structures for the metal complexes.

\subsection{Anti-Microbial Activities}

The antimicrobial activities of the ligands and the metal(II) complexes against different strains of microbes are presented in Table 4 with a minimum inhibitory concentration of 10 $\mathrm{mg} / \mathrm{mL}$. The synthesized compounds were tested against eight micro-organisms consisting of four Gram positive and four Gram negative bacteria. The HL was expectedly weakly active against the strains of microbes. However, the copper complexes showed considerable activities, which is the highest among the synthesized ligands. Likewise, $\left[\mathrm{Ni}(\mathrm{ASA}) \mathrm{HL}\left(\mathrm{H}_{2} \mathrm{O}\right)_{2}\right]$ showed some activities with an inhibitory zone of $10 \mathrm{~mm}$ against Shigella spp. In summary the activity obtained was lesser than the standard.

Table 4. Zone of inhibition of synthesized Compounds ( $\mathrm{mm}$ ).

\begin{tabular}{|c|c|c|c|c|c|c|c|c|}
\hline Microorganisms/Compounds & Staph. spp & Strept. spp & B. cereuspp & B. subtilis & E. coli & Vibro spp & Salmonella spp & Shigela spp \\
\hline HL & - & - & - & - & - & - & - & - \\
\hline HASA & - & 22 & 20 & 24 & 4 & 20 & 22 & 18 \\
\hline [Co(ASA)HL $\left.\left(\mathrm{H}_{2} \mathrm{O}\right) \mathrm{Cl}\right]$ & - & - & - & - & - & - & - & - \\
\hline$\left[\mathrm{Ni}(\mathrm{ASA}) \mathrm{L}\left(\mathrm{H}_{2} \mathrm{O}\right)_{2}\right]$ & - & - & - & - & - & - & - & 10 \\
\hline$\left[\mathrm{Cu}(\mathrm{ASA}) \mathrm{L}\left(\mathrm{H}_{2} \mathrm{O}\right)_{2}\right]$ & - & 6 & - & 2 & - & 4 & - & - \\
\hline N. C(sterilized distilled water) & - & - & - & - & - & - & - & - \\
\hline Streptomycin & 20 & 24 & 22 & 14 & 2 & 20 & 24 & 20 \\
\hline
\end{tabular}

\section{Conclusion}

The synthesis of $\mathrm{Co}(\mathrm{II}), \mathrm{Ni}(\mathrm{II})$ and $\mathrm{Cu}(\mathrm{II})$ complexes of aspirin mixed with $m$-hydroxylbenzaldehyde-4-nitrobenzoylhydrazone (L) and their characterization were carried out via UV-visible spectroscopy, infrared spectroscopy, metal analysis, conductivity and magnetic measurements. 
The mixed ligand complexes displayed variety of colours ranging from yellow to green, possess high melting points and insoluble in water with conductivity values of less than 5 $\Omega^{-1} \mathrm{~cm}^{2} \mathrm{~mol}^{-1}$ indicating the covalent nature of these complexes. The UV-Visible spectra in conjunction with the magnetic moments suggested an octahedral geometry for these mixed ligand complexes. The mixed ligand complexes displayed lower activity against the tested bacteria in comparison with the chosen standard.

\section{References}

[1] Baligar R. S., Revankar V. K. (2006) Coordination diversity of new mononucleating hydrazone in $3 \mathrm{~d}$ metal Complexes: synthesis, characterization and structural studies. Journal of Serbian Chemical Society, 71 (12), 1301-1310.

[2] El-Halima B. D., Hanan F., Omar M. M., Gehad M. G. (2011) Synthesis, structural, thermal studies and biological activity of a tridentate schiff base ligand and their transition metal complexes. Spectrochemical Acta Part A, 78, 36-44.

[3] Gupta A. K., Pall R., Beniwal V. (2014) Novel dehydroacetic acid based hydrazine schiff's base metal complexes of first transition series: synthesis and biological evaluation study. World Journal of Pharmacy and Pharmaceutical Sciences, 4 (1), 990-1008.

[4] Hania M. M. (2009) Synthesis and antibacterial activity of some transition metal complexes of oxime, semicarbazone and phenylhydrazone, E-journal of Chemistry, 6 (1), 508-514.

[5] Hollander, M. D. (1994) Gastrointestinal complications of non-steroidal anti-Inflammatory drugs: prophylactic and therapeutic strategies. American Journal of Medicine, 96: 274281.

[6] Kamini J. D. (2015) Spectroscopy and structure of transition metal complexes of hydrazone derivatives. Journal of Pharmacy Research, 9 (4), 299-305.

[7] Köse, D. A., Hasan I., Hacali N. (2007) Synthesis and characterization of the nicotinamide-acetylsalicylato complexes of $\mathrm{Co}(\mathrm{II}), \mathrm{Ni}(\mathrm{II}), \mathrm{Cu}(\mathrm{II})$, and $\mathrm{Zn}(\mathrm{II})$. Hacettepe Journal of Biology \& Chemistry, 35 (2) 123-128.

[8] Lawal A., Obaleye, J. A. (2005) Synthesis, characterization and antibacterial activity of aspirin and paracetamol-metal complexes. Journal of Biochemistry, 19, 9-15.
[9] Lee J. D. Concise Inorganic Chemistry. $5^{\text {th }}$ edition. India: Blackwell Science Limited. 2005, 205-324.

[10] Leuner C., Dressmann J. (2002) Improving Drug Solubility for Oral Delivery Using Solid Dispersions. European Journal of Pharmacy: BioPharm, 54, 107-112.

[11] Mahal A., Abu-El-Halawa R., Zabin S. A., Ibrahim M., Kaimari A. T. (2015) Synthesis, characterization and antifungal activity of some metal complexes derived from quinoxaloylhydrazone. World Journal of Organic Chemistry, 3 (1), $1-8$.

[12] Mohammed M. A., Mohammed S. J. (2012) Synthesis and characterization of $\mathrm{Co}(\mathrm{II}), \mathrm{Ni}(\mathrm{II}), \mathrm{Cu}(\mathrm{II}), \mathrm{Zn}$ (II) and $\mathrm{Cd}(\mathrm{II})$ complexes with aroylhydrazonemonoximes. Science Journal Article, 23 (4): 51-69.

[13] Mtrei R., Yadawa M., Patil, S. A. (1996) Synthesis of biologically active p-bis(amino-5- mercapto-1,2,4-triazol-3-yl) benzene and its schiff base: new class of bis-triazole. Orient Journal of Chemistry, 12, 101-102.

[14] Olanrewaju, A. A., Oni, T. I. Osowole, A. A. (2016) Synthesis, Characterization and Antioxidant Properties of Some Metal(II) Complexes of Mixed Drugs Vitamin Bx and Aspirin. Chemistry Research Journal, 2016, 1 (4), 90-96.

[15] Geary W. J. (1971) The use of conductivity measurements in organic solvents for the characterisation of coordination compounds. Coordination Chemistry Reviews, 7 (1), 81-122.

[16] Osowole A. A., Wakil S. M., Alao O. K. (2015) Inorganic synthesis, characterization and antimicrobial activity of some mixed trimethoprim-sulfamethoxazole metal drug complexes. World Applied Sciences Journal, 33 (2), 336-342.

[17] Padmini K., Jaya P., Divya M., Rohini P., Lohita M., Swetha, K., Kaladar P. (2013) A Review on Biological Importance of Hydrazones. International Journal of Pharma Research \& Review, 2 (8), 43-58.

[18] Pouralimardan O., Chamayou A. C., Jniak C., Monfared H. H. (2007) Hydrazone Schiff base Manganese (II) Complexes: Synthesis, Crystal Structure and Catalytic Reactivity. Inorganica Chemica Acta, 360 (5), 1599-1608.

[19] Ajayeoba, T. A., Akinyele, O. F., Ayeni, A. O., Olawuni. I. J. (2019) Synthesis, Characterisation and Acetylcholinesterase Inhibition Activity of Nickel(II) and Copper(II) Complexes of 3-Hydroxybenzaldehyde-4-nitrobenzoic Acid Hydrazone. American Journal of Applied Chemistry. Vol. 7 (2), 64-71. 